\title{
Transient climate response to solar irradiance: reconstruction for the last 120 years
}

\author{
J. C. Gérard ${ }^{1}$, D. A. Hauglustaine ${ }^{2}$ \\ 'Institut d'Astrophysique, Université de Liège, B-4000 Liège, Belgium \\ ${ }^{2}$ Service d'Aeronomie du CNRS, Université de Paris VI, F-75230 Paris, France
}

\begin{abstract}
Secular variations of the solar constant are frequently invoked as a possible source of long-term climatic changes. Various solar forcing functions have been proposed to explain the possible periodicities found in climatic records. Recently, Foukal \& Lean (1990; Science 247: 556-558) proposed a reconstruction of the total solar irradiance based on satellite observations of the last solar cycle. In this paper, we combine this solar forcing with a zonally averaged seasonal climatc: model to evaluate the transient climatic response to this new reconstruction. Comparison is made with previous modelled climatic response to solar irradiance changes. The latitudinal distribution of the transient temperature change in response to this solar forcing is also investigated. We conclude that, if a significant part of the global temperature increase over the last decades is of solar origin, sunspot blocking and facular activity contribute a negligible amount to the observed global temperature trend.
\end{abstract}

\section{INTRODUCTION}

Variations of global surface temperature over the last century have been reported on the basis of measurements of continental air (CAT) (Hansen \& Lebedeff 1988, Jones 1988, Vinnokov et al. 1987), marine air (MAT) (Folland et al. 1984) and sea-surface (SST) (Folland et al. 1984) temperatures compiled in different data bases. All data sets are in basic agreement and exhibit an almost continuous warming trend punctuated with periods of constant or decreasing temperature (Jones et al. 1988). Variations of the solar luminosity can be invoked as an external forcing mechanism in addition to other factors, such as enhanced greenhouse efficiency, aerosols or natural variability of the climate system, to explain the climatic changes observed over the last $100 \mathrm{yr}$. It is therefore of interest to assess the relative role of this factor in order to be able to determine quantitatively the importance of the warming due to enhanced concentrations of trace gases added to the atmosphere during the industrial era.

The determination of the secular variation of the solar luminosity and its potential effects on the surface temperature have been a subject of speculation. Since the pioneer work of Sellers (1969), the response of the climate system to strong solar variability over geologic ages has been intensively studied (see for example the review of North et al. 1981). Also, a variation of solar constant of a few percent is currently used as a sensitivity test of climate models to investigate, for example, the ice snow albedo feedback (Robock 1978) or, more recently, the vegetation masking feedback (Harvey 1988a). A temperature response range of 1.1 to $2.3^{\circ} \mathrm{C}$ for a $1 \%$ solar total irradiance increase is predicted by climate models (Gérard 1990). Concerning the transient response, climate models have also been used to determine possible solar signatures in the recent past evolution of the temperature, but a major limitation to these works is the inadequate knowledge of the secular variation of the solar irradiance. Various formulations were proposed, based on the use of indirect indicators. For example, several studies were based on an assumed positive irradiance-sunspot number correlation (Schneider \& Mass 1975, Robock 1979). Others assumed sinusoidal variations of solar irradiance with frequencies derived from data such as solar diameter and with amplitudes and phases tuned to reproduce observed climatic records (Gilliland 1982, North et al. 1983, Wigley 1988). Reid (1987) linked the variations of solar irradiance to the envelope of the 11 yr cycle of solar activity. This approach was also adopted and refined later by Reid \& Gage (1988) and Reid (1991). Other studies derived reconstructions based on a 
fitting technique in order to match the past $10 \mathrm{yr}$ observed with space instruments (Hoffert et al. 1988. Schatten 1988). Most of these works were based on box-models without spatial resolution or with models neglecting ice/snow albedo feedbacks. Since the climatic response to forcing is governed by high latitude ice/snow albedo feedbacks and changes in meridional heat transport, it is useful to simulate climatic response to solar forcings with a latitudinal model including detailed surface albedo feedback parameterization. Further, it is necessary to take into account the damping and delay introduced by the deep ocean thermal inertia and to investigate the transient response instead of an equilibrium approach.

Recently, Foukal \& Lean (1990) proposed a new technique to reconstruct the solar irradiance $S$ of the last $125 \mathrm{yr}$ in a way similar to that adopted to calculate $\Delta S$ values since 1874 (Foukal \& Lean 1988). This method is based on the understanding of the irradiance variations observed with satellites and has been shown to reproduce with reasonable accuracy the irradiance variations observed with the ACRIM and ERB instruments since 1981. The brightening of the sun during periods of activity is mostly ascribed to the facular activity which overcomes the opposed effect of blocking by sunspots. Since facular indices are not directly available for periods before 1946, the sunspot number $R$ was used as a proxy to the facular contribution to the solar irradiance. This factor was combined with the sunspot area index $A$ to reconstruct the solar irradiance over the past century.

In this article we refine and investigate further the results of Gérard \& Hauglustaine (1989) calculating the transient temperature variations associated with this recent reconstruction of the solar irradiance change using a zonally averaged seasonal climate model. We then compare our results with the expected equilibrium response and describe the model response to larger secular irradiance variations possibly due to other physical processes in the sun's interior.

\section{THE CLIMATE MODEL}

The climate model used for this investigation is conceptually similar to the models developed by Harvey (1986b) and Ledley (1988) and is described in some detail in studies of the latitudinal distribution of the warming due to trace gases (Hauglustaine et al. 1989, Hauglustaine \& Gérard 1991). This $1 \frac{1}{2}-\mathrm{D}$ energybalance model extends from. $85^{\circ} \mathrm{S}$ to $85^{\circ} \mathrm{N}$ with a latitudinal resolution of $5^{\circ}$ and has an atmospheresurface-deep ocean partitioning. The atmospheric and oceanic meridional energy fluxes are proportional to the meridional temperature gradient with coefficients derived from observations. The oceanic mixed layer depth is seasonally and latitudinally dependent. In order to conserve energy as the mixed layer changes depth with season, an interactive shallow lower layer has been added. This deep ocean layer exchanges mass with the mixed layer such that their combined depth is constant (Thompson \& Schneider 1979). In each latitudinal bin a surface and atmospheric landocean resolution is adopted. For each surface type, the atmospheric absorption, transmission and reflection as well as the energy fluxes at the ground (sensible heat, latent heat, infrared fluxes) are computed. The seasonal cycle of solar radiation reaching the top of the atmosphere and the solar zenith angle are computed and diurnally averaged. Solar fluxes at the surface are calculated using the formulation of Thompson \& Barron (1981). Cloud cover is assumed to be a single layer with cloud fraction set, at each grid point, to the observed zonally averaged total mean monthly cloud amount. Surface albedos are calculated taking into account snow and sea-ice covers, which are obtained from empirical temperature-dependent parameterizations (Robock 1983). The heat exchange between marine and continental regions is proportional to the temperature difference between the 2 atmospheric boxes with empirical coefficients (Harvey 1988b). In each latitudinal zone, the temperature of each of the 5 systems (atmosphere over land, atmosphere over ocean, land, mixed layer and deep ocean layer) is computed using the thermodynamic equation. Comparisons between madel-simulated present climate and climatic data show that the model reproduces well the annual cycle of the surface and surface air temperature on land and ocean.

Various sensitivity tests have shown that the model has a global mean temperature response of $3.2^{\circ} \mathrm{C}$ to an abrupt atmospheric $\mathrm{CO}_{2}$ doubling. The climate feedback parameter $\lambda=\Delta Q / \Delta T=1.27 \mathrm{~W} \mathrm{~m}{ }^{-2}{ }^{\circ} \mathrm{C}^{-1}$ (where $\Delta Q$ is the radiation forcing at the tropopause and $\Delta T$ the induced surface temperature perturbation) lies within the range of most recent models (Ramanathan 1988). The sensitivity of models to changes in solar irradiance is frequently expressed in terms of a parameter $\beta=S \mathrm{~d} T / \mathrm{d} S$. The value of $\beta$ for this model is $195^{\circ} \mathrm{C}$, in good agreement with other EBM and GCM climate models. The modelled transient solution of climate to external forcings shows that the equilibrium is reached approximately exponentially with a characteristic 'e-folding time' $\tau_{e}$. This parameter depends on the total inertia of the system and consequently on the rate of heat exchange between the mixed-layer and the deep ocean. In this model, the e-folding time depends on the adopted deep ocean thermal inertia [see Hauglustaine \& Gérard (1991) for a further description]. 
Without energy exchange between mixed layer and deep ocean, we obtain $\tau_{\mathrm{e}}=5$ yr. When the coupling between surface layer and bottom layer is introduced, $\tau_{\mathrm{e}}$ ranges from 30 to $530 \mathrm{yr}$ for a deep ocean thermal inertia $\left(C_{\text {do }}\right)$ ranging respectively from 10 to 200 times the mixed layer inertia $\left(C_{1 \mathrm{ml}}\right)$. In this work, a value $C_{\text {do }}=15 \times C_{m !}$ is adopted. This leads to $\tau_{\mathrm{e}}=$ $42 \mathrm{yr}$, a middle value of the range given, for example, by Schlesinger (1986). Following Wigley \& Schlesinger (1985), an effective thermal diffusivity $\kappa$ of about $1.5 \mathrm{~cm}^{2} \mathrm{~s}^{-1}$ may be deduced from this value of $\tau_{\mathrm{e}}$.

\section{NUMERICAL SIMULATIONS}

Fig. 1A reproduces the solar irradiance change as calculated by Foukal \& Lean (1990). A gradual increase in total irradiance since 1945 is calculated, continuing to the present. The maximum relative variation over this period is about $6 \times 10^{-4}$ and took place during solar cycle 21, which was unusually strong. We now describe the results of numerical simulations of the global surface temperature change of the last 120 yr calculated with our $1 \frac{1}{2}-\mathrm{D}$ seasonal model. Fig. 1B shows the temperature change ob-
Fig. 1. (A) Reconstruction of relative total solar irradiance since 1874 based on sunspot blocking and facular components (Foukal \& Lean 1990). (B) Temperature variation calculated in Case 1 $(-)$, Case $2(-\ldots)$ and Case $3(\ldots$. using the solar forcing function shown in (A). See text for description of cases
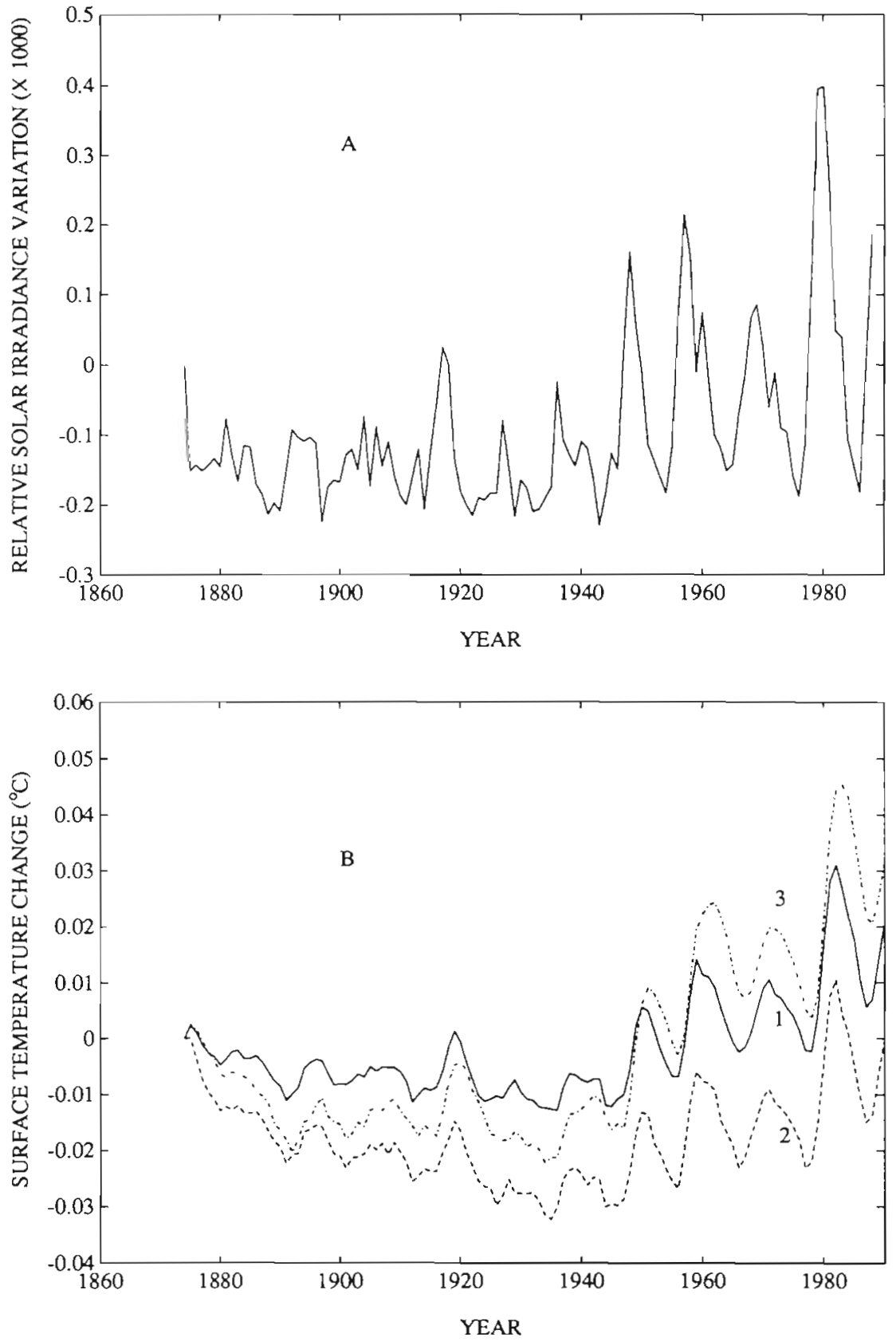


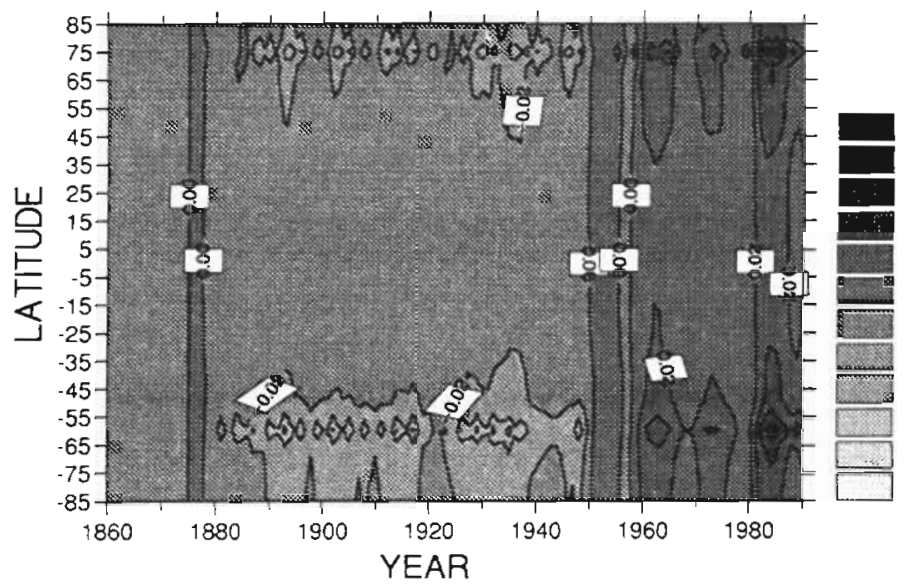

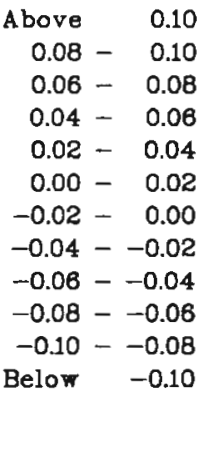

Fig. 2. Latitudinal distribution of the transient temperature change calculated for Case $3\left({ }^{\circ} \mathrm{C}\right)$ tained under various assumptions with the irradiance curve in Fig. 1A. The computed climatic response to solar irradiance variations is obtained by calculating the deviation from a steady state (fixed irradiance) control run. Since the history of solar irradiance before 1874 is unknown, assumptions have to be made to evaluate the importance of this factor on the calculated temperature evolution. In Case 1 the solar irradiance before 1874 is set to its mean value calculated over the entire reconstruction period 1874 to $1988\left(\bar{S}=1367.47 \mathrm{~W} \mathrm{~m}^{-2}\right)$. In Case 2 , the mean value of $S$ for the year 1874 is adopted to initialize the system. A series of $11 \mathrm{yr}$ peaks is observed with the largest amplitudes occurring after 1930. They correspond to maxima in the reconstructed time-series of the solar constant. In Case 1, little change is calculated before the second part of the century whereas in Case 2, a fairly well-defined minimum is obtained in the early $1940 \mathrm{~s}$. This feature is due to the fact that the mean $S$ value for 1874 is significantly larger than the average value of the following years. This stresses the important role played by the initial model conditions on the simulated transient response. The largest modulation is associated with cycle 12 which was unusually pronounced compared to the previous $100 \mathrm{yr}$. Case 3 is similar to Case 1 but in order to investigate the role played by the ocean thermal inertia, the coupling between the mixed layer and the deep ocean is removed. In Case 3, the amplitude of the 11 yr moduIation of the global temperature is larger as a consequence of the damping induced by the inertia of the ocean in Case 1. The maximum temperature change between the low irradiance period before 1940 and the higher values in the early $1980 \mathrm{~s}$ is $0.067^{\circ} \mathrm{C}$ for Case 3 in comparison to $0.044^{\circ} \mathrm{C}$ for Case 1 . The relative variation of the solar irradiance reconstruction for this period of about $6 \times 10^{-4}$ coupled with the $\beta$ equilibrjum feedback parameter of this model predicts a steady-state temperature change $\Delta T$ of $0.12^{\circ} \mathrm{C}$. The comparison between predicted and simulated temperature response shows that the damping due to ocean inertia is between 40 and $60 \%$

In any case, the amplitude is thus considerably smaller than the ca $0.6{ }^{\circ} \mathrm{C}$ variation observed since the beginning of the century. Further, no significant correlation between observed data and reconstructed temperature change (Case 1) appears from these results. The same conclusion of small direct effects of Foukal \& Lean's (1990) reconstructed solar irradiance on global-mean temperature has been reached from simple EBM calculations in an independent study (Wigley \& Raper 1990).

Fig. 2 illustrates the latitudinal distribution of the surface temperature change corresponding to Case 3 . Since the climatic response is governed by ice/snow albedo feedbacks, maximum temperature changes are located in northern and southern hemisphere high latitudes during both climate warming and cooling periods. The climate response is centered at $75^{\circ}$ in the northern hemisphere and at $60^{\circ}$ in the southern hemisphere. This interhemispheric asymmetry is due to the different sea ice and snow cover distributions in the 2 hemispheres. Like the solar forcing, the climate response exhibits a high variability from 1880 to 1950 and clear maxima (corresponding to maximum solar activity) after 1960. A maximum temperature increase of $0.1^{\circ} \mathrm{C}$ is reached at $60^{\circ} \mathrm{S}$ in 1984 and a maximum. cooling of $0.07^{\circ} \mathrm{C}$ is obtained at the same latitude in 1935.

In order to compare this result with a previous solar reconstruction, we now examine the time evolution of the global surface temperature calculated with the time-dependent $S$ value of Reid (1987). Reid's results show a time variation which resembles the SST global curve of Folland et al. (1984), with a minimum between 1900 and 1920 and a warming trend since then, with the exception of a dip around 1970. The total amplitude is about $0.5^{\circ} \mathrm{C}$, in reasonable agreement with 
Fig. 3. (A) Time variation of the relative total solar irradiance based on a solar sunspot index formulation. (B) Temperature variation calculated using the solar forcing function shown in (A)
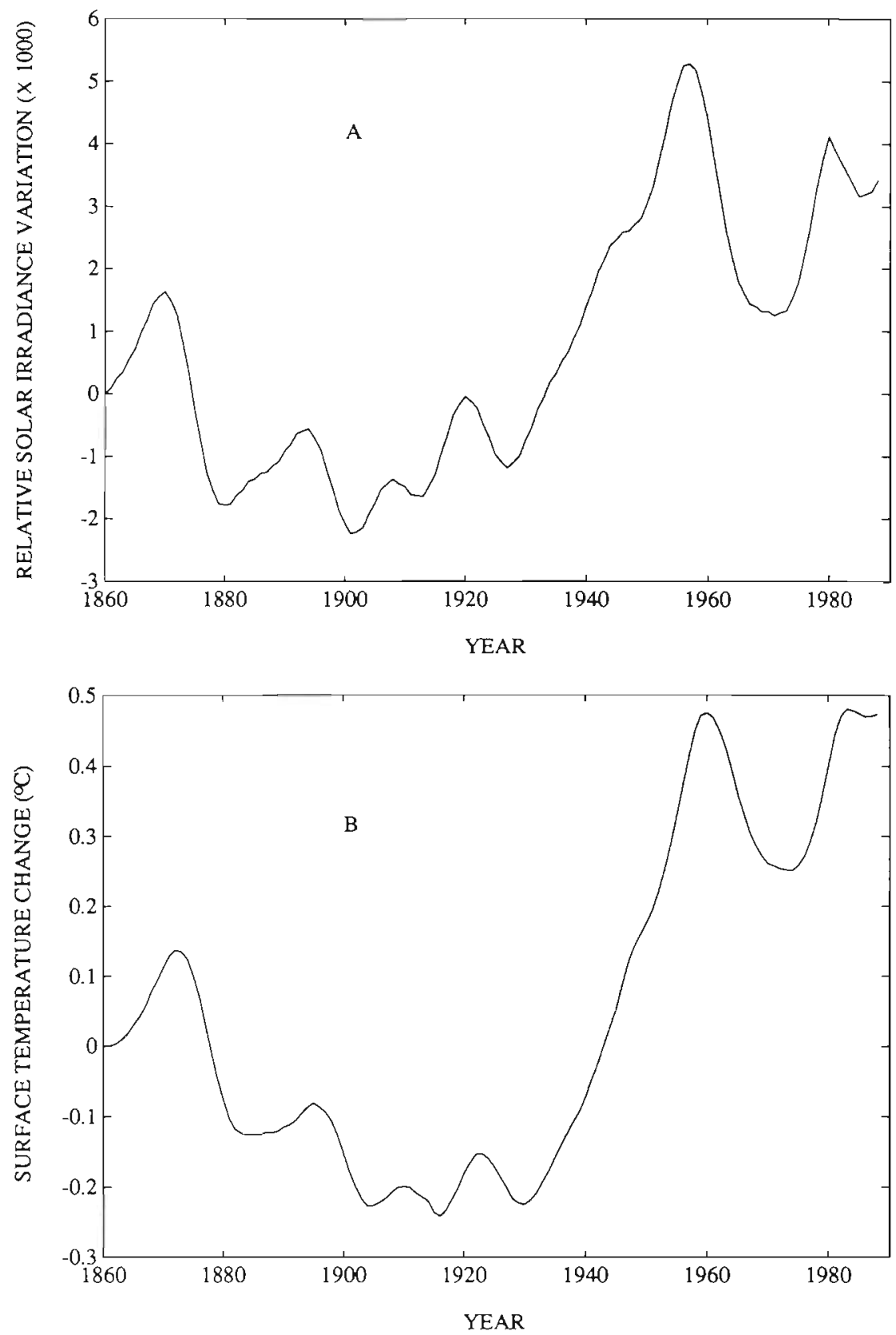

SST observations. In an attempt to explain the SST observations compiled by Folland et al. (1984), which suggest the presence of a 80 yr Gleissberg periodicity, Reid (1987) proposed a linear relationship between the sunspot number average over $11 \mathrm{yr} \bar{R}$ and the solar luminosity $S$ :

$$
S(t)=S_{0}+\alpha S_{0}\left(\bar{R}-R_{0}\right)
$$

where $S_{0}$ and $R_{0}$ are reference values for $S$ and $R$ respectively. A value of $1.08 \times 10^{-4}$ was determined for the proportionality coefficient $\alpha$ on the basis of a fit to the SST data by Folland et al. (1984). The relative solar irradiance variation given by this relation is plotted in Fig. 3A. For the period from early 1980 to the present, the irradiance values observed with the ACRIM experiments are used and the reference value $S_{0}$ is chosen to ensure continuity with the pre-1980 calculated values. Not surprisingly, since $\alpha$ is used as a tunable parameter, in this case the temperature change reaches a maximum of about $0.7^{\circ} \mathrm{C}$, similar to the observations (Fig. 3B). We note, however, that the additional warming due to the accumulation of greenhouse gases would accentuate the calculated warming trend. Reid \& Gage (1988) and Reid (1991) indicated that the inclusion of this component reduces the consistency be- 


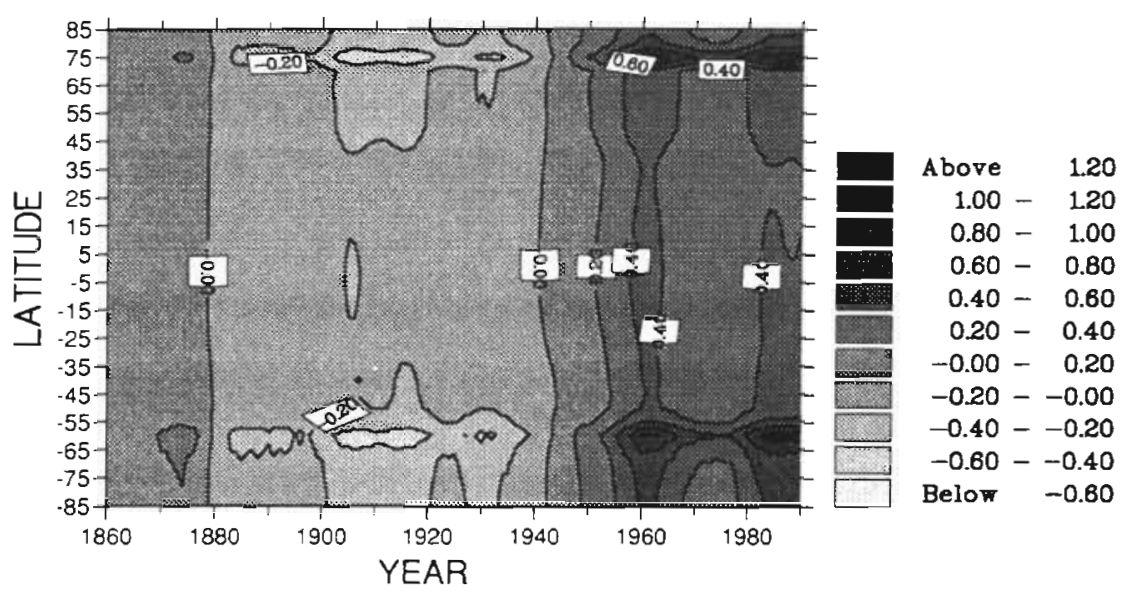

Fig. 4. Latitudinal distribution of the transient temperature change calculated using the solar forcing function of Fig. $3 \mathrm{~A}\left({ }^{\circ} \mathrm{C}\right)$ tween observed and calculated temperatures. Similar results have been obtained with this model.

The latitudinal distribution of the temperature change calculated in this case is shown in Fig. 4. As in Fig. 2, the maxima are located at high latitudes. In this experiment, a general cooling is obtained during the period 1880 to 1940 reaching $-0.56^{\circ} \mathrm{C}$ in 1985 in southern polar regions. A warming after 1940 is calculated which reaches $1.2^{\circ} \mathrm{C}$ in 1985 in the same region.

\section{CONCLUSIONS}

Climate simulations using a zonally averaged seasonal model have been performed to investigate the response of the global climate system to possible secular changes in the solar irradiance forcing. Expressions proposed in the past to model variations of the solar luminosity yield temperature changes comparable in amplitude to the warming trend observed during this century. However, this agreement may be fortuitous since they were based on tunable solar forcing simulations and since no physical basis exists to justify the use of simple expressions based solely on the sunspot index as an indicator of solar output. A recent reconstruction of the solar irradiance of the past 120 yr gives a global temperature change of a. few hundredths of a degree, independently of the scenario adopted for the irradiance history before 1874 and of the strength of the exchanges between the surface and deep ocean. The warming predicted by the model is, in this case, considerably less than the observed temperature trend. This is inconsistent with the hypothesis of significant solar forcing of historical climate variations, because if one were to assume a much greater climatic sensitivity, due for example to cloud feedback, the greenhouse forcing would still dominate. This is because the radiative forcing due to accumulated infrared active gases is on the order of $2 \mathrm{~W} \mathrm{~m} \mathrm{~m}^{-2}$, whereas it is less than $0.1 \mathrm{~W} \mathrm{~m}^{-2}$ in the solar irradiance reconstruction. The latitudinal distribution of the temperature change shows that surface albedo feedbacks play an important role during both warming and cooling periods. Pronounced maxima are obtained at high latitudes after 1960 corresponding to maximum solar activity.

It is thus concluded that, if the climatic evolution is controlled in part by solar activity, other factors than the photospheric and chromospheric indices must be used to describe the evolution of the solar output and its secular evolution. For example, a changing magnetic field in the solar convection zone would possibly be able to produce luminosity changes reaching $1 \%$ (Gilliland 1989 ).

Acknowledgements. One of the authors (J.C.G.) is supported by the Belgian Foundation for Scientific Reseach (FNRS) and is grateful to the Impulse Program 'Global Change' supported by the Belgian State, Prime Minister's Service, Science Policy Office. D.A.H. is under contract with the Commission of the European Communities, Sectoral Grant in Sciences and Technology no. B/87000569.

\section{LITERATURE CITED}

Folland, C. K., Parker, D. E., Kates, F. E. (1984). Worldwide marine temperature fluctuations. Nature, Lond. 310: $670-673$

Foukal, P., Lean, J. (1988). Magnetic modulation of solar luminosity by photospheric activity. Astrophys. J. 328: 347-357

Foukal, P., Lean, J. (1990). A model of total solar irradiance variations between 1874-1988. Science 247: 556-558

Gérard, J. C. (1990). Modelling the climate response to solar variability. Phil. Trans. R. Soc. Lond. A.330: 561-574

Gérard, J. C., Hauglustaine, D. A. (1989). Climatic response to solar variability: simulations with a seasonal energy balance model. In: Crutzen, P. J., Gérard, J. C., Zander, R. (eds.) Proceedings of the 28th Liege Astrophysical Colloquium 'Our changing Atmosphere' Université de Liège, p. $325-331$ 
Gilliland, R. L. (1982). Solar, volcanic, and $\mathrm{CO}_{2}$ forcing of recent climatic changes. Clim. Change 4: 111-131

Gilliland, R. L. (1989). Solar evolution. Global planet. Change 1: $35-56$

Hansen, J., Lebedeff, S. (1988). Global surface air temperatures: update through 1987. Geophys. Res. Lett. 15: $323-326$

Harvey, L. D. (1988a). On the role of high latitude ice, snow, and vegetation masking feedbacks in the climatic response to external forcing changes. Clim. Change 13: $191-224$

Harvey, L. D. (1988b). A semianalytic energy balance model with explicit sea ice and snow physics. J. Clim. 1: 1065-1085

Hauglustaine, D. A., Gérard, J. C., Brasseur, G. (1989) Climatic warming due to increasing trace gases: simulations with a seasonal energy balance model. In: Crutzen, P. J., Gérard, J. C., Zander, R. (eds.) Proceedings of the 28th Liège Astrophysical Colloquium 'Our changing Atmosphere' Université de Liège, p. 317-322

Hauglustaine, D. A., Gérard, J. C. (1991). Present and future CFC and other trace gas warming: results from a seasonal climate model. Ann. Geophys. 9: 571-587

Hoffert, M., Frei, A., Narayanan, V. J. (1988). Application of SOLAR MAX ACRIM data to analysis of solar driven climatic variability on Earth. Clim. Change 13: 267-285

Jones, P. D. (1988). Hemisphere surface air temperature variations: recent trends and update. J. Clim. 1. 654-660

Jones, P. D., Wigley, T, M., Folland, C. K., Parker, D. E., Angell, J. K., Lebedeff, S., Hansen, J. E. (1988). Evidence for global warming in the past decade. Nature, Lond. 338 : $790-791$

Ledley, T. S. (1988). A coupled energy balance climate-sea ice model: impact of sea ice and leads on climate. J. geophys. Res. 93: 15 910-15932

North, G. R., Cahalan, R. F., Coakley, J. A. (1981). Energy balance climate models. Rev. Geophys. Space Phys. 19: 91-121

North, G. R., Mengel, J. G., Short, D. A. (1983). Climatic response to a time varying solar constant. In: McCormac, B. M. (ed.) Weather and climate responses to solar variations. Colorado Associated University Press, Colorado, p. $243-255$

Ramanathan, V (1988). The greenhouse theory of climate change: a test by inadvertent global experiment. Science 240: $293-299$

Reid, G. C. (1987). lnfluence of solar variability on global sea surface temperatures. Nature, Lond. 329: 142-143

Editor: G. Esser
Reid, G. C. (1991). Solar total irradiance variation and the global sea surface temperature record. J. geophys. Res 96: $2835-2844$

Reid, G. C., Gage, K. S. (1988). The climatic impact of secular variations in solar irradiance. In: Stephenson, F. R., Wolfendale, A. W. (eds.) Secular solar and geomagnetic variations in the last 10,000 years. Kluwer Publishers, Dordrecht, p. 225-243

Robock, A. (1978). Internally and externally caused climates change. J. Atmos. Sci. 35: 1111-1122

Robock, A. (1979). The little ice age: northern hemisphere averaged observations and model calculations. Science 206: 1402-1404

Robock, A. (1983). Ice and snow feedbacks and the latitudinal and seasonal distribution of climate sensitivity. J. Atmos. Sci. 40: $986-997$

Schatten, K. H. (1988). A model for solar constant secular changes. Geophys. Res. Lett. 15: 121-124

Schlesinger, S. H. (1986). Equilibrium and transient climatic warming induced by increased atmospheric $\mathrm{CO}_{2}$. Clim. Dyn. 1: 35-51

Schneider, S. H., Mass, C. (1975). Volcanic dust, sunspots and temperature trends. Science 190: 741-746

Sellers, W. D. (1969). A global climatic model based on the energy balance of the earth-atmosphere system. J. appl. Meteorol. 8: 392-400

Thompson, S. L., Schneider, S. H. (1979). A seasonal zonal energy balance climate model with an interactive lower layer. J. geophys. Res. 84: 2401-2414

Thompson, S. L., Barron, E. J. (1981). Comparison of Cretaceous and present earth albedos: implications for the causes of paleoclimate. J. Geol. 89: 143-167

Vinnokov, K. Y., Groisman, P. Y., Lugina, K. M., Golubev, A A. (1987). Variations in northern hemisphere surfaces air temperature over 1841-1985. Meteorol. Hydrol. 1987(1): $45-53$

Wigley, T. M. L. (1988). The climate of the past 10,000 years and the role of the sun. In: Stephenson, F. R., Wolfendale, A. W. (eds.) Secular solar and geomagnetic variations in the last 10,000 years. Kluwer Publishers, Drordrecht, p. 209-224

Wigley, T. M. L., Schlesinger, M. E. (1985). Analytical solution for the effect on increasing $\mathrm{CO}_{2}$ on global mean temperature. Nature, Lond. 315: 649-652

Wigley, T. M. L., Raper, S. C. B. (1990). Climatic change due to solar irradiance changes. Geophys. Res. Lett. 17: $2169-2172$

Manuscript first received: December 3, 1990

Revised version accepted: Auqust 22, 1991 